\title{
Najpogostejša socialna problematika oseb po amputaciji spodnjih udov v Univerzitetnem rehabilitacijskem inštitutu Republike Slovenije - Soča
}

\begin{abstract}
Članek temelji na rezultatih raziskave o socialnem delu z osebami po amputaciji spodnjih udov na Oddelku za rehabilitacijo pacientov po amputacijiv Univerzitetnem rehabilitacijskem inštitutu Republike Slovenije - Soča, kjer je socialna delavka članica multidisciplinarnega tima. Je prva raziskava v Sloveniji, ki preučuje najpogostejšo socialno problematiko, v kateri se znajdejo osebe po amputaciji spodnjega uda. Rezultati raziskave so pokazali, da je bila večina oseb po amputaciji spodnjih udov in njihovih bližnjih slabo informirana o programih podpore in pomoči v domačem okolju, o pravicah v socialnem varstvu, zdravstvenem, pokojninskem in invalidskem zavarovanju. Najpogosteje so doživljali stiske in težave, povezane z oskrbo, podporo in urejanjem pravic po koncu rehabilitacije, s socialnim vključevanjem v skupnost, vožnjo avtomobila in socialno-ekonomskim statusom.
\end{abstract}

Ključne besede: socialno delo, rehabilitacija, pravice invalidov, timsko delo, biopsihosocialni pristop, multidisciplinarni tim.

Jolanda Stevanović je univerzitetna diplomirana socialna delavka, zaposlena na Oddelku za rehabilitacijo pacientov po amputaciji na Univerzitetnem rehabilitacijskem inštitutu Republike Slovenije - Soča. Kontakt: jolanda.stevanovic@ir-rs.si.

Katja Ronchi je univerzitetna diplomirana socialna delavka, zaposlena na Oddelku za rehabilitacijo pacientov po poškodbah, s perifernimiživčnimi okvarami in revmatskimi obolenji na Univerzitetnem rehabilitacijskem inštitutu Republike Slovenije - Soča. Kontakt: katja.ronchi@ir-rs.si.

Aljana Grčko Gradišar je magistrica socialnega dela, zaposlena na Oddelku za rehabilitacijo pacientov po amputaciji na Univerzitetnem rehabilitacijskem inštitutu Republike Slovenije - Soča. Kontakt: aljana.grcko@ir-rs.si.

\section{The most frequent social problems of people after lower limb amputation at} the University Rehabilitation Institute of the Republic of Slovenia - Soča

The paper is based on a research study about social work with people after lower limb amputation at the University Rehabilitation Institute of the Republic of Slovenia - Soča, Department for rehabilitation of patients after amputation, where a social worker is a member of a multidisciplinary medicine rehabilitation team. It is the first social work study in Slovenia addressing the most frequent social problems of people after lower limb amputation. The results indicate that the majority of individuals after lower limb amputation and their relatives are poorly informed about the possibilities for help at home and the rights arising from disability, as well as with the possibilities and procedures of obtaining the rights pertaining to social, health and disability insurance. Individuals were facing difficulties in various areas, such as care and support at home, social inclusion into the community, car driving, socioeconomic status and administrative procedures.

Key words:social work, rehabilitation, disability rights, team work, biopsychosocial approach, multidisciplinary team.

Jolanda Stevanovic is a social worker at the University Rehabilitation Institute of the Republic of Slovenia - Soča, Department for rehabilitation of patients after amputation. Contact: jolanda.stevanovic@ir-rs.si.

Katja Ronchi is a social worker at the University Rehabilitation Institute of the Republic of Slovenia - Soča, Department for rehabilitation of patients after injuries, with peripheral nervous impairments and rheumatologoic diseases. Contact: katja.ronchi@ir-rs.si.

Aljana Grčko Gradišar is a social worker at the University Rehabilitation Institute of the Republic of Slovenia - Soča, Department for rehabilitation of patients after amputation. Contact: aljana.grcko@ir-rs.si. 


\section{Uvod}

Amputacija pomeni izgubo oziroma odstranitev uda, dela uda ali drugega telesnega organa in je posledica poškodbe ali bolezni (Brejc, 2009). Mednarodna klasifikacija funkcioniranja, zmanjšane zmožnosti in zdravja ${ }^{1}(2006$, str. 213) amputacijo uvršča med okvare; okvara je opredeljena kot izguba ali nepravilnost v telesni strukturi ali fiziološki funkciji. Danes je v razvitem svetu okoli $90 \%$ amputacij spodnjih udov posledica srčno-žilnih obolenj, nekaj pa jih je posledica poškodb, tumorjev in prirojenih nepravilnosti udov (prav tam).

V Sloveniji na leto opravijo približno 400-500 amputacij spodnjih udov zaradi žilnih obolenj (pogostejša incidenca je pri pacientih ${ }^{2} \mathrm{~s}$ sladkorno boleznijo) (Prešeren Štrukelj, 2003; Burger, 2014). Pogostost amputacij se povečuje s starostjo, in sicer je pri starosti 60 let okoli 93 amputacij na 100.000 prebivalcev (Prešeren Štrukelj, 2003). Po predvidevanjih se bo število amputacij do leta 2050 podvojilo (Ziegler-Graham, MacKenzie, Ephraim, Travison in Brookmeyer, 2008). Poglavitne vzroke za povečanje števila amputiranih oseb lahko pripišemo staranju populacije in povečanju števila kroničnih obolenj sladkorne bolezni in bolezni perifernih arterij (prav tam).

Amputacija uda povzroči hudo okvaro s prizadetostjo in pogosto tudi oviranostjo. To je še posebej izrazito pri osebah po amputaciji obeh spodnjih udov. $V$ življenje posameznika vnaša omejitve in lahko za uporabnika pomeni izgubo številnih vrednot: fizičnega funkcioniranja, telesnega videza in socialnih interakcij (Prešeren Štrukelj, 2002). Amputacija spodnjega uda pogosto povzroči slabšo pokretnost, s tem pa se poveča tveganje za nastanek srčnega infarkta, možganske kapi in pljučne embolije (pridružene bolezni) (Prešeren Štrukelj, 2003).

\section{Rehabilitacija v Univerzitetnem rehabilitacijskem inštitutu - Soča}

Univerzitetni rehabilitacijski inštitut - Soča (v nadaljevanju URI - Soča) je osrednji nacionalni zdravstveni zavod, specializiran za celostno rehabilitacijo pacientov z okvarami in z gibanjem povezanimi omejitvami. Zaradi njih je se uporabniki težje vključujejo v dejavnosti, med drugim so omejeni tudi pri delu (Stevanović, Pirnat in Ronchi, 2012). Rehabilitacija ljudi po amputaciji je proces, ki se začne pred operacijo in konča z vrnitvijo človeka v družbo (Burger, 2010, str. 114). Po amputaciji je uporabnik napoten na triažni pregled na URI - Soča. Ob izpolnjevanju meril za sprejem je pozneje vabljen na rehabilitacijsko obravnavo na Oddelek za rehabilitacijo pacientov po amputaciji.

1 Mednarodna klasifikacija funkcioniranja, zmanjšane zmožnosti in zdravja je klasifikacija zdravstvenih značilnosti oseb v okviru njihovih individualnih življenjskih okoliščin in vplivov okolja. Upošteva odnos med zdravstvenimi značilnostmi in spremljajočimi dejavniki, ki povzroči zmanjšano zmožnost oziroma invalidnost. Izdala jo je Svetovna zdravstvena organizacija.

2 Pacient je uporabnik zdravstvenih storitev. V članku uporabljamo izraz uporabnik, razen v primeru dobesednih navedkov in sklicevanj na avtorje s področja zdravstvene dejavnosti. Pacient je po Zakonu o pacientovih pravicah (2008) uporabnik zdravstvenih storitev v odnosu do zdravstvenih delavcev. Pacient ima pravice kot uporabnica ali uporabnik zdravstvenih storitev. 
Rehabilitacijska obravnava temelji na kombinirani in koordinirani uporabi medicinskih, psiholoških, socialnih in edukacijskih metod, s pomočjo katerih lahko usposobimo uporabnika po amputaciji za optimalno funkcionalno stanje (Marinček, 2002). Tak način dela je znan tudi kot biopsihosocialni model (Kuret in Osolnik, 2018; Bambič, 2008). Pri njem sta v ospredju odnosna raven in partnerski odnos članov tima z uporabnikom. Biopsihosocialni pristop poskuša zagotoviti sintezo, usklajen pogled na zdravje iz različnih zornih kotov - biološkega, osebnega in družbenega (Mednarodna klasifikacija funkcioniranja, zmanjšane zmožnosti in zdravja, 2006, str. 20). Tak način dela spodbuja uporabnikovo samoučinkovitost po zaslugi kakovostnega komunikacijskega odnosa, ki je podlaga uspešne rehabilitacije. Delo je usmerjeno v izboljšanje funkcij in zmanjševanje posledic zaradi bolezni oziroma poškodbe (Štefančič, 2003), v samem procesu ima uporabnik aktivno vlogo (Resolucija o nacionalnem planu zdravstvenega varstva 2016-2025, 2016). Poglavitni cilj rehabilitacije oseb po amputaciji spodnjega uda je približati se psihofizičnemu in socialnemu stanju pred amputacijo (Burger in Kuret, 2016; Pohjolainen, Alaranta in Karkkaienen, 1990).

Za celovito rehabilitacijsko obravnavo je potreben timski pristop (Štefančič, 2003) oziroma multidisciplinarna timska obravnava. Na oddelku za rehabilitacijo po amputaciji deluje multidisciplinaren tim, kot ga določajo Klinične smernice za rehabilitacijo oseb po amputaciji (Burger, 2014): zdravnik specialist fizikalne in rehabilitacijske medicine, zdravnik internist, diplomirana medicinska sestra, srednja medicinska sestra, delovni terapevt, fizioterapevt, socialna delavka ${ }^{3}$, psiholog in inženir protetike. Multidisciplinaren pristop strokovnjakom omogoča, da se lažje uskladijo in da s svojimi storitvami upoštevajo prioritetne potrebe uporabnika (Grušovnik, 2010). To pomeni, da ob sprejemu uporabnika na oddelek določimo kratkoročne in tudi dolgoročne cilje. Izid rehabilitacijske obravnave je odvisen od več dejavnikov: sodelovanja v rehabilitacijskem programu, ravni amputacije ${ }^{4}$, spremljajočih bolezni (Burger, 2010; Prešeren Štrukelj, 2002) in vzroka za amputacijo - na primer, pri ljudeh, amputiranih zaradi bolezni perifernih žil, je izid slabši kot pri amputiranih zaradi poškodbe ali drugega vzroka (Burger in Kuret, 2016).

\section{Delo socialne delavke v URI - Soča}

Oseba $\mathrm{z}$ amputacijo se zaradi bolezni ali poškodbe znajde $\mathrm{v}$ novi, neznani situaciji in je v stiski. Sprememba zdravstvenega stanja poleg samih telesnih sprememb uporabnika in svojce pogosto čustveno obremeni s strahovi in bojaznijo glede razpleta in nadaljnje stopnje samostojnosti (Stevanović, Pirnat in Ronchi, 2012). Prav tu se pojavi prostor za socialno delo, saj je pomemben del celostne obravnave in pomeni pomoč uporabnikom, ki so se znašli v psihosocialni stiski zaradi zdravstvenih težav.

4 Ravni amputacije: $v$ grobem razlikujemo nadkolenske amputacije, amputacije skozi koleno, podkolenske amputacije, amputacije skozi gleženj in transmetatarzalne (polovica stopal) amputacije (Praznik, 2016). Amputacija je lahko enostranska ali obojestranska (bilateralna). 
Amputacija pri človeku povzroči ranljivost in negotovost, načeta je njegova samopodoba, od socialne delavke potrebuje predvsem zaupen odnos, ki temelji na spoštovanju in zaupanju. Socialna delavka po načelu individualnega načrtovanja skupaj z uporabnikom in njegovim sistemom razišče njegov življenjski svet, analizira indeks potreb, oblikuje cilje in strategijo, krepi njegovo moč in išče vire moči v vseh fazah rehabilitacije. V okviru delovnega odnosa se osebi in svojcem približa in pomaga pri soustvarjanju rešitev, ki so za vse udeležene čim bolj sprejemljive in uresničljive (Stevanović, Pirnat in Ronchi, 2012). Zagotavlja podporo uporabnikom in njihovim bližnjim pri prilagajanju na nove razmere, pri njihovi vključitvi v proces rehabilitacije, pri iskanju ustreznih oblik podpore in storitev (Strategija socialnega dela $\mathrm{v}$ zdravstveni dejavnosti - predlog, 2013).

Socialna delavka uporabniku na razumljiv način poda vse potrebne informacije, da lahko prevzame aktivno vlogo $v$ celostnem procesu rehabilitacije. $\mathrm{Z}$ uporabnikom vzpostavita sodelovanje, da lahko cilje in rešitve skupaj z uporabnikom definirata, redefinirata, se dogovorita in izpeljeta dogovorjeno.

Socialna delavka $v$ odnosu $z$ uporabnikom in svojci prevzema različne vloge - povezovalke, pobudnice, učiteljice, zagovornice, svetovalke, posrednice in koordinatorke (Miloševič Arnold, 2000; Eržen, 2012). Ocenjuje potrebe in tveganja, funkcionalne sposobnosti, materialne vire in vire moči, družinska razmerja in življenjske situacije (Ronchi, Stevanović, Skok in Pirnat, 2016). Pri svojem delu uporablja metode, ki omogočajo posege na vseh ravneh sistema - je most med uporabnikom, svojci, multidisciplinarnim timom, skupnostjo in drugimi službami na terenu (Stevanović, Pirnat in Ronchi, 2012).

\section{Raziskava}

Namen raziskave je bil ugotoviti, katere so najpogostejše težave z vidika socialnega dela pri uporabnikih po amputaciji spodnjega uda in katere so najpogostejše socialnodelavske storitve oziroma aktivnosti.

\section{Metoda}

Raziskava je potekala v Univerzitetnem rehabilitacijskem inštitutu Republike Slovenija - Soča leta 2017. Izvedena je bila retrospektivna kvantitativna študija. Podatki so bili zbrani iz dokumentacije socialne obravnave na vzorcu naključno izbranih 180 uporabnikov, vključenih v hospitalno obravnavo leta 2017. Viri podatkov so bili pogovori z uporabniki, svojci in različnimi institucijami ter pregled zdravstvene dokumentacije. Podatki so bili statistično obdelani z vrtljivo tabelo v programu Excel. $V$ tabelo smo med drugim vnesli podatke o spolu, starosti, socialnoekonomskem statusu, s kom uporabnik živi in kdo mu zagotavlja pomoč, ali je oseba prejela protezo in katere so bile oblike pomoči v sklopu socialne obravnave. Študijo je odobrila Etična komisija URI - Soča (številka 22/2018). Rezultati so bili objavljeni na konferenci Mednarodnega združenja za protetiko in ortotiko (ISPO), ki je potekala od 20. do 22. septembra 2018 v Portorožu. 
Rezultati

V vzorcu raziskave je prevladovala moška populacija (71 \%), 78 \% vseh uporabnikov je imelo status upokojenca (starostno, predčasno, invalidsko ali vdovsko upokojeni), 7 \% jih je bilo v delovnem razmerju (razlog za amputacijo je bila v večini primerov poškodba). Petnajst odstotkov uporabnikov je imelo nižji socialnoekonomski status, to so bili posamezniki brez zaposlitve in brez prejemkov ali brez zaposlitve in z denarno socialno pomočjo ali nadomestilom iz Zavoda Republike Slovenije za zaposlovanje.

Socialna vključenost/bivanjska situacija ob sprejemu:

- $v$ domačem okolju je živelo $88 \%$ uporabnikov,

- $66 \%$ uporabnikov je živelo z družino oziroma s sorodniki ali prijatelji,

- $22 \%$ uporabnikov je živelo samih (razvezani, ovdoveli, samski),

- 12 \% uporabnikov je prišlo iz domov za starejše občane ali socialnovarstvenih zavodov (institucionalna oblika namestitve).

Socialna vključenost/bivanjska situacija ob odpustu:

Socialna delavka je uporabnike in svojce informirala o mreži pomoči v domačem okolju in postopkih za sprejem v institucionalno namestitev in tako zagotovila, da je bila odločitev sprejeta na podlagi pregleda vseh možnosti.

- $83 \%$ uporabnikov se je vrnilo v domače okolje,

- $16,5 \%$ uporabnikov je odšlo v institucionalno namestitev,

- 1 oseba je odšla v podaljšano bolnišnično zdravljenje.

Uspešnost socialnodelavske obravnave in multidisciplinarnega tima se kaže v izjemno majhnem deležu uporabnikov (5\%), ki se po rehabilitacijski obravnavi niso mogli vrniti $v$ domače okolje.

Razlogi za namestitev v institucionalno varstvo so bili:

- nezmožnost samostojnega življenja,

- niso imeli socialne mreže, ki bi lahko zagotovila ustrezen obseg pomoči in podpore,

- ureditev storitve pomoči na domu ni bilo možno zagotoviti v potrebnem obsegu (npr. zaradi zmanjšanja kognitivnih funkcij).

Pri urejanju namestitve $v$ institucionalno varstvo nikomur od uporabnikov ni bila odvzeta sposobnost za odločanje (ni bilo sproženega postopka za odvzem poslovne sposobnosti), ne glede na morebitno zmanjšanje kognitivnih sposobnosti. Pri uporabnikih, ki so se morali preseliti iz domačega okolja v institucionalno namestitev, je bila pozornost namenjena razlagi, podpori, pogovoru z uporabnikom in s svojci ter urejanju vsega potrebnega za selitev.

\section{Najpogostejše socialnodelavske aktivnosti in storitve ${ }^{5}$}

Vsi uporabniki in $65 \%$ svojcev je potrebovalo informiranje, svetovanje in podporo. Strokovno svetovanje, informiranje in podpora socialne delavke zagotavljajo čustveno razbremenitev in zaupnost pogovora ter uporabnikom omogočajo avtonomno odločanje. Informiranje definiramo kot seznanitev z vsemi pravicami, ki izhajajo iz sprememb zdravstvenega stanja. Svetovanje

5 Socialnodelavske storitve $v$ zdravstveni dejavnosti še niso formalno odpredeljene. Postopek za formalno priznanje storitev $v$ zdravstvu še poteka. 
pomeni usmerjanje in podajanje predlogov za uveljavljanje določenih pravic. Socialna delavka s podporo spodbuja, motivira in izvaja aktivnosti za načrtovanje in uresničevanje definiranih ciljev.

Graf 1: Najpogostejša področja socialne pomoči in storitev.

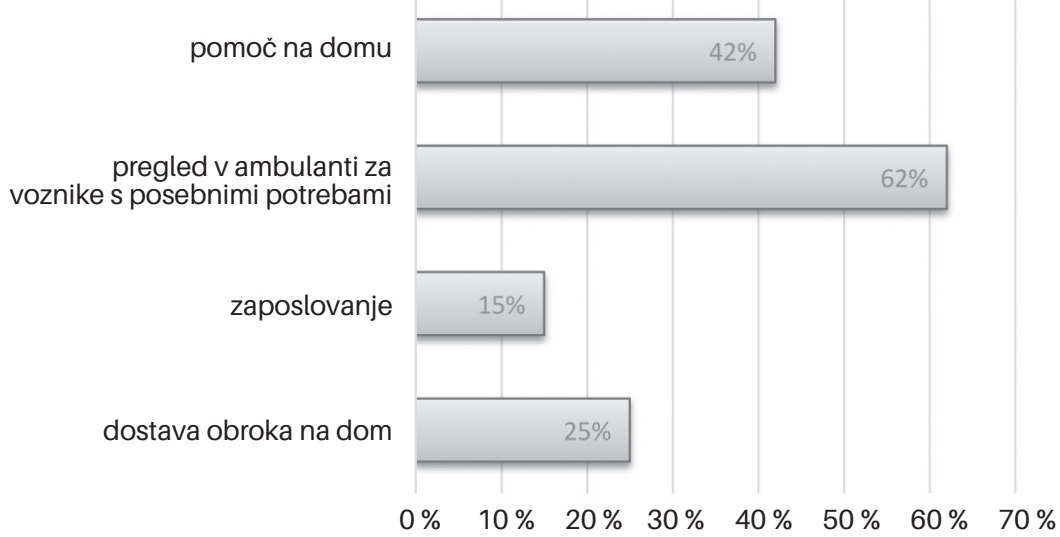

Uporabniki so najpogosteje izražali stisko na področjih vožnje avtomobila, pomoči na domu, dostave hrane na dom in zaposlitve:

- $62 \%$ uporabnikov je potrebovalo informacije glede pregleda v ambulanti za voznike s posebnimi potrebami, s sočasno predstavitvijo zakonodaje s tega področja; socialna delavka je $v$ tem primeru vezni člen med uporabnikom in ambulanto za voznike s posebnimi potrebami;

- $42 \%$ uporabnikov je potrebovalo informacijo oziroma pomoč ali podporo pri vključitvi storitve pomoč na domu;

- $25 \%$ uporabnikov je potrebovalo informacije in pomoč pri ureditvi dostave kosila na dom;

- $15 \%$ uporabnikov je potrebovalo informacije in svetovanje na področju vključevanja na trg dela ali vračanja na delo (pomoč pri vzpostavitvi stika $\mathrm{z}$ delodajalcem, sodelovanje s Centrom za poklicno rehabilitacijo oziroma svetovanje in podporo pri ustrezni predstavitvi na invalidski komisiji).

Pri načrtovanju odpusta je medinstitucionalno sodelovanje ustaljena praksa socialne delavke na oddelku amputacij. Za obdobje raziskave je socialna delavka sodelovala:

- s centrom za socialno delo (27\%),

- z izvajalci storitve pomoč na domu (26\%),

- z Zavodom za pokojninsko in invalidsko zavarovanje (16\%),

- $\mathrm{z}$ domovi za starejše občane (14\%),

- z drugimi: občinami, zdravstvenimi domovi, društvi, zavodom za zaposlovanje.

Intenzivnost socialne obravnave je bila večja pri uporabnikih, ki niso dobili medicinsko-tehničnega pripomočka (proteze), in pri uporabnikih, ki so živeli sami (22 \%). Socialna obravnava je bila pri njih osredotočena na pomoč pri iskanju ustreznih oblik pomoči in storitev, ki omogočajo vrnitev v domače okolje, na povezovanje z zunanjimi institucijami, na pomoč pri iskanju ter uresničevanju pravic do socialne varnosti (72\%) in pravic iz pokojninskega in invalidskega zavarovanja (89\%). 
Razprava

Namen raziskave je bilo ugotoviti najpogostejšo socialno problematiko oseb po amputaciji spodnjih udov, ki so bili sprejeti na Oddelek za rehabilitacijo pacientov po amputaciji v URI - Soča. Pregled tako svetovnih kot domačih strokovnih in znanstvenih del je pokazal, da za zdaj ne obstaja študija, ki bi neposredno povezovala socialno delo z ljudmi po amputaciji spodnjih udov na način in v obsegu naše raziskave. Objavljene so predvsem študije z vidika psihološke adaptacije na amputacijo (Reichman in Bartman, 2018; Gudelj-Velaga, 2016; Hanley, Jensen, Ehde, Hoffman, Patterson in Robinson, 2004; Rybarczyk, Edwards in Behel, 2004; MacKenzie, Wegener, 2016) oziroma raziskave, ki se osredotočajo na določen socialni vidik, na primer zaposlitev in pomen podpore neformalne socialne mreže (Burger, 2016; Valizadeh, Dadkhah, Mohammadi in Hassankhani, 2014; Pohjolainen, Alaranta in Karkkainen, 1990) ter vključevanje pomoči na domu (Pohjolainen, Alaranta in Karkkainen, 1990).

Amputacija je v večini primerov posledica zapletov v zdravstvenem stanju zaradi pridruženih bolezni (najpogosteje zapletov pri sladkorni bolezni in periferni arterijski bolezni). Po podatkih Organizacije za gospodarsko sodelovanje in razvoj je Slovenija na zadnjem mestu po številu amputacij spodnjih udov zaradi zapletov, povezanih s sladkorno boleznijo (Resolucija o nacionalnem planu zdravstvenega varstva 2016-2025, 2016). Glede na to, da se pogostost amputacij s starostjo veča in da smo v raziskavi odkrili, da je 81,7 odstotkov uporabnikov na oddelku za rehabilitacijo po amputaciji starejših od šestdeset let, lahko predvidevamo, da bo v prihodnosti potreba po socialni obravnavi na oddelku za rehabilitacijo po amputaciji še večja.

Pomoč in podpora svojcev je zelo pomemben vir (po)moči. Podporo družine in vrstnikov Valizadeh, Dadkhah, Mohammadi in Hassankhani (2014) oprededeljujejo kot pomemben dejavnik v procesu rehabilitacije osebe $\mathrm{z}$ amputacijo. Podobno so v svoji študiji ugotovili Pedras, Vilhena, Carvalho in Pereira (2018); menijo, da prejeta podpora uporabnikove socialne mreže prevzame vlogo mediatorja med travmatskim stresnim sindromom in prilagajanjem na omejitve. Ugotovitve druge študije iz tujine (Williams, Ehde, Smith, Czerniecki, Hoffman in Robinson, 2004) so, da se starejše, samske, razvezane in ovdovele osebe slabše socialno reintegrirajo v obdobju dveh let po amputaciji. Rybarczyk, Edwards in Behel (2004) so ugotovili, da samske osebe in uporabniki brez podporne mreže v skupnosti doživljajo več depresije in anksioznosti. Avtorji srbske študije (Jovanović in Pejović, 2000) in hrvaške študije (Gudelj-Velaga, 2018) so raziskovali psihosocialni vidik prilagoditve po amputaciji in ugotovili podobno: osamljene osebe bolj žalujejo zaradi amputacije kot tiste, ki imajo dobro podporo bližnjih. Naša raziskava teh rezultatov ne more niti ovreči niti potrditi, je pa pokazala, da je bila socialna obravnava intenzivnejša pri ljudeh, ki živijo sami in imajo šibko socialno mrežo.

Naša raziskava je potrdila, da je bilo pri načrtovanju odpusta nujno medinstitucionalno sodelovanje, če smo želeli zagotoviti varno in kakovostno življenje po koncu rehabilitacije v URI - Soča. Socialna delavka je ključna oseba pri aktiviranju strokovnih služb na terenu. Z uporabnikovim dovoljenjem in njegovim sodelovanjem preda natančno izbrane informacije o njegovem 
zdravstvenem stanju, o njegovih potrebah in željah izvajalcem pomoči na domu, strokovnim sodelavcem na pristojnem centru za socialno delo in po potrebi osebnemu zdravniku. Pohjolainen, Alaranta in Karkkaienen (1990) so preprični, da vrnitev $\mathrm{v}$ domače okolje ne bi bila uspešna brez aktivnega sodelovanja socialne delavke $\mathrm{v}$ zdravstveni dejavnosti in pomoči na domu ter določenih prilagoditev bivalnega okolja.

Na podlagi raziskave smo ugotovili, da so bili uporabniki in svojci slabo informirani o možnih oblikah pomoči $\mathrm{v}$ domačem okolju in postopkih za ohranjanje ali uveljavljanje pravic s področja socialnega varstva, zdravstvenega varstva ter pokojninskega in invalidskega zavarovanja. Upravičenost do določene pravice zaradi invalidnosti ne pomeni tudi samodejne pridobitve te pravice. Socialna delavka pojasni pogoje in protokol za uveljavljanje pravic in pogosto tudi neposredno pomaga izpolniti za marsikaterega uporabnika težko razumljive obrazce. Uporabniki so se najpogosteje srečevali z izzivi s področja oskrbe v domačem okolju, vključevanja v skupnost, ohranitve zadovoljivega socialnoekonomskega statusa, izpolnjevanja vlog za uveljavljanje pravic (administrativni del) in vožnje avtomobila. Sposobnost za nadaljnjo vožnjo avtomobila se je pokazala kot pomemben dejavnik pri kakovosti uporabnikovega življenja, saj se mu tako zmanjša odvisnost od pomoči drugih, bolj je lahko vključen v družbo, izobraževanje in zaposlitev. Lažje obiskuje kulturne, športne in zabavne prireditve. Za uporabnikovo samozavest je pomembno tudi že samo to, da je sposoben voziti in ohranjati samostojnost (Zupan in Marinček, 2013). Engkasan, Ehsan in Chung (2011) na podlagi svoje raziskave poročajo, da je bila le približno polovica ljudi po amputaciji spodnjega uda sposobna za nadaljnjo vožnjo avtomobila in da je bil eden poglavitnih razlogov za to, da niso vozili, svojci, ki so vožnjo prepovedali. Naša raziskava ne omogoča takšne primerjave, nihče od uporabnikov ni navajal, da bi ga svojci ovirali pri želji po nadaljnji vožnji avtomobila. Prav tako iz raziskave ne moremo razbrati, koliko uporabnikov je bilo sposobnih za nadaljno vožnjo avtomobila.

K normalizaciji življenja po amputaciji veliko pripomore tudi nadaljevanje pridobitnega dela. Mlajši uporabniki, ki jih lahko opredelimo kot delovno aktivno populacijo, so bili zaskrbljeni zaradi vračanja na delo oziroma vključevanja na trg dela. Poudarili so, da je zaposlitev pomembna za njihovo dobro počutje, za občutek o lastni vrednosti, za prispevek v skupnost, za zagotovitev socialnoekonomskega statusa ter za utrjevanje in širjenje (podporne) socialne mreže. Razumevajoč delodajalec in kolegialni odnosi na delovnem mestu lahko pomembno pripomorejo $\mathrm{k}$ hitrejši prilagoditvi na novo stanje in k vračanju $\mathrm{v}$ običajno življenje (Valizadeh, Dadkhah, Mohammadi in Hassankhani, 2014).

Raziskovalci Bruins, Geertzen, Groothoff in Schoppen (2003) so ugotovili, da sta bila kot najpomembnejša razloga za vrnitev na delovno mesto po amputaciji omenjena vrednotenje zaposlitve $\mathrm{z}$ vidika organizacije dneva in socialni stiki. Osebe s kroničnimi boleznimi so poudarjale pomen dela v povezavi s samospoštovanjem, rednim prihodkom in uresničevanjem življenjskega namena (prav tam). Po podatkih študije Burger in Marincek (2007) se približno $66 \%$ uporabnikov po amputaciji vrne na delo, od tega jih od 22 do 67 \% zadrži isto delovno mesto, drugi pa so morali službo zamenjati. 
Največja omejitev naše študije je nesledljivost. Ne moremo preveriti, katere od predlaganih storitev so uporabniki po odpustu upoštevali in realizirali, katerih ne in kaj so bili poglavitni razlogi, da jih niso realizirali. Za nadaljnje študije bi bilo zanimivo raziskati povezavo med posameznimi dejavniki oziroma sovplivanje ožjih področij (posameznih segmentov) življenjskega sveta uporabnika. Na primer, neposredne posledice amputacije na nadaljnjo sposobnost za vožnjo avtomobila ali posledice amputacije na vrnitev na delo oziroma vključitev na trg dela.

\section{Sklep}

Naša kvantitativna študija je po tematiki in načinu zbiranja podatkov izvirna, takšne študije so v stroki socialnega dela maloštevilne. Enopomensko definicijo o najpogostejši socialni problematiki oseb po amputaciji je težko podati. Raziskava je potrdila, da je delo socialne delavke na oddelku za rehabilitacijo pacientov po amputaciji pestro in najpogosteje posega na področja socialnega, zdravstvenega varstva ter invalidskega in pokojninskega zavarovanja. Vsaka obravnava je enkraten delovni proces in se razlikuje glede na psihofizične zmožnosti uporabnika, njegovo socialno mrežo, status, potrebe po pomoči, oporo v skupnosti in želene izide. Hkrati se kaže pomembnost zgodnje vključitve uporabnika v socialno obravnavo, torej takoj ob sprejemu na rehabilitacijo, saj se lahko tako pravočasno ukvarjamo z množico za uporabnike pomembnih segmentov njegovega življenjskega sveta in s tem povečamo možnost za kakovostno življenje po amputaciji oziroma kljub njej.

\section{Viri}

Bambič, M. (2008). Biopsihosocialni model zdravja (Diplomska naloga). Ljubljana: Fakulteta za socialno delo.

Brejc, T. (2009). Rehabilitacijski besednjak. Ljubljana: Univerzitetni rehabilitacijski inštitut Republike Slovenije - Soča.

Bruins, M., Geertzen, J. H., Groothoff, J. W., \& Schoppen, T. (2003). Vocational reintegration after a lower limb amputation: a qualitative study. Prosthetics and Orthotics International, 27, 4-10.

Burger, H., \& Marincek, C. (2007). Return to work after lower limb amputation. Disability and Rehabilitation, 29(17), 1323-1329.

Burger, H., (2010). Rehabilitacija ljudi po amputaciji. Rehabilitacija, IX, 114.

Burger, H. (2014). Klinične smernice za rehabilitacijo oseb po amputaciji spodnjega uda. Rehabilitacija, XIII, 116-122.

Burger, H. (2016). Vocational considerations after amputations. V J. I. Krajbich, M. S. Pinzur, B. K., Potter, \& P. M. Stevens (ur.), Atlas of amputation and limb deficiencies, 2, 4. izd. Rosemont, IL: American Academy of Orthopaedic Surgeons (str. 739-742).

Burger, H., \& Kuret, Z. (2016). Ocenjevanje bolnikov po amputaciji - od amputacije do popolne reintegracije. Rehabilitacija, XV, 77-82.

Engkasan, P. J., Ehsan, F., \& Chung, T. (2011). Ability to return to driving after major lowerlimb amputation. Journal of Rehabilitation Medicine: Official Jounal of the UEMS European Board of Physical and Rehabilitation Medicine, 44(1), 19-23.

Eržen, I. (2012). Socialno delo v zdravstveni dejavnosti. Socialno delo, 51(1-3), 15-26. 
Grušovnik, M. (2010). Delovanje multidisciplinarnih timov in sodelovanje socialnih delavcev z drugimi strokovnjaki (Diplomsko delo). Ljubljana: Fakulteta za socialno delo.

Gudelj-Velaga, I. (2018). Psihosocijalna prilagodba bolesnika poslije amputacije donjeg ekstremiteta. Sestrinski glasnik, 23(1), 36-45. Pridobljeno 12. 11. 2021 s https://hrcak. srce.hr/198926

Hanley, M. A., Jensen, M. P., Ehde, D. M., Hoffman, A. J., Patterson, D. R., \& Robinson, L. R. (2004). Psychosocial predictors of long-term adjustment to lower-limb amputation and phantom limb pain. Disability and Rehabilitation, 26(14/15), 882-893.

Jovanović, A., \& Pejović, M. (2000). Psihosocialni i biomedicinski aspekti adaptacije na amputaciju ekstremiteta. Engrami, 22(3-4), 83-99.

Kuret, Z., \& Osolnik, B. (2018). Vloga pacienta pri določanju ciljev v rehabilitaciji (bolnikov s kronično bolečino). Rehabilitacija, XVII, 21-28.

MacKenzie, E., \& Wegener, S. T. (2016). Psychological adaptation to limb amputation. V J. I. Krajbich, M. S. Pinzur, B. K. Potter, \& P. M. Stevens (ur.), Atlas of amputation and limb deficiencies, 2, 4. izd. Rosemont, IL: American Academy of Orthopaedic Surgeons (str. 719-726).

Marinček, Č. (2002). Amputacije in protetika danes. V H. Burger (ur.), Amputacije in protetika (str. 27-33). Ljubljana: Inštitut Republike Slovenije za rehabilitacijo.

Mednarodna klasifikacija funkcioniranja, zmanjšane zmožnosti in zdravja (2006). Ljubljana: Inštitut za varovanje zdravja Republike Slovenije in Inštitut Republike Slovenije za rehabilitacijo.

Miloševič-Arnold, V. (2000). Profesionalne vloge socialnih delavcev pri delu s starimi ljudmi. Socialno delo, 39(4-5), 253-262.

Pedras S., Vilhena E., Carvalho R., \& Pereira M G. (2018). Psychosocial adjustment to a lower limb amputation ten months after surgery, 63(3), 418-430.

Pohjolainen, T., Alaranta, H., \& Karkkaienen, M. (1990). Prosthetic use and functional and social outcome following major lower limb amputation. Prosthetics and Orthotics International, 14, 75-79.

Praznik, N. (2016). Amputacija okončine ali njenih delov, informacije za paciente. Pridobljeno 14. 12. 2020 s https://www.sb-celje.si/media/files/dokumenti/Nasveti_\%C5\%BEilna/ Zilna\%20krg_AMPUTACIJA_internet.pdf

Prešern Štrukelj, M. (2002). Rehabilitacija starejših po amputaciji spodnjih udov zaradi žilne bolezni. V H. Burger (ur.), Amputacije in protetika (str. 27-33). Ljubljana: Inštitut Republike Slovenije za rehabilitacijo.

Prešern Štrukelj, M. (2003). Rehabilitacija bolnikov po amputaciji udov. V M. Štefančič (ur.), Osnove fizikalne medicine in rehabilitacije gibalnega sistema (str. 309-318). Ljubljana: DZS.

Reichmann, J. P., \& Bartman, K. R. (2018). An integrative review of peer support for patients undergoing major limb amputation. Journal of Vascular Nursing, XXXVI(1), 34-39.

Resolucija o nacionalnem planu zdravstvenega varstva 2016-2025 (2016). » Skupaj za družbo zdravja « (ReNPZV16-25). Ur. l. RS, št. 25/16.

Ronchi, K., Stevanovič, J., Skok, V., \& Pirnat, B. (2016). Pomen ocenjevanja funkcioniranja od akutne faze do popolne reintegracije - izziv za socialno delo $v$ medicinski rehabilitaciji. Rehabilitacija, XV, 61-65.

Rybarczyk, B., Edwards, R., \& Behel, J. (2004). Diversity in adjustment to a leg amputation: case illustrations of common themes. Disability and Rehabilitation, 26(14/15), 944-953.

Stevanović, J., Pirnat, B., \& Ronchi, K. (2012). Socialno delo v Univerzitetnem rehabilitacijskem inštitutu Republike Slovenije - Soča. Socialno delo, 51(1-3), 165-170.

Strategija socialnega dela v zdravstveni dejavnosti - predlog (2013). Ljubljana: Ministrstvo za zdravje (str. 1-41).

Štefančič, M. (2003). Fizikalna terapija, fizikalna medicina, rehabilitacija. V M. Štefančič (ur.), Osnove fizikalne medicine in rehabilitacije gibalnega sistema (str. 15-19). Ljubljana: DZS.

Valizadeh, S., Dadkhah, B., Mohammadi, E., \& Hassankhani, H. (2014). The perception of trauma patients from social support in adjustment to lower-limb amputation. Indian Journal of Palliative Care, 20(3), 229-238. 
Williams, R., Ehde, D., Smith, D., Czerniecki, J., Hoffman, A., \& Robinson, L. (2004). A two year longitudinal study of social support following amputation. Disability and Rehabilitation, 26(14-15), 862-874.

Zakon o pacientovih pravicah (2008). Ur. l. RS, št. 15/08.

Ziegler-Graham, K., MacKenzie, E. J., Ephraim, P. L., Travison, T. G., \& Brookmeyer, R. (2008). Estimating the prevalence of limb loss in the United States: 2005 to 2050. Archives of Physical Medicine and Rehabilitation, 89, 422-429.

Zupan, A., \& Marinček, Č. (2013). Ocenjevanje vozniških sposobnosti in potrebne prilagoditve avtomobila. Rehabilitacija, XII, 36-44. 
